\title{
NIETZSCHE E DÜHRING: RESSENTIMENTO, VINGANÇA E JUSTIÇA.
}

\author{
Antonio Edmilson Paschoal \\ Pontifícia Universidade Católica do Paraná/CNPq
}

\begin{abstract}
The analysis of the sources that Nietzsche makes use to elaborate the concepts he develops in his philosophy revealed itself one of the most efficient means to study his thought. In this paper, we intend to reflect upon the way Nietzsche utilizes Dühring's theses as well as those of the Berlin's professor as he contests them in his work, On the Genealogy of Morals. The hypothesis that guides this study is this: in spite of the severe critiques with which Nietzsche receives Dühring's theses and the caustic manner by which he refers himself to the Berlin's professor, he assigns to his adversary an important role, principally when he deals with the themes of justice and resentment.

Keywords: Nietzsche, Dühring, resentment, vengeance, justice.
\end{abstract}

Resumo: A análise das diferentes fontes que Nietzsche lança mão para a elaboração dos conceitos que utiliza em sua filosofia tem se mostrado um dos meios mais profícuos para 0 estudo do pensamento do filósofo de Naumburg. Neste artigo pretendemos discorrer sobre 0 modo como Nietzsche se serve tanto de teses de Dühring quanto do próprio professor de Berlim na argumentação que desenvolve em Para a genealogia da moral. A hipótese que norteia este estudo é que, a despeito da dura crítica com a qual Nietzsche recebe as teses de Dühring e do modo mordaz que se refere ao professor de Berlim, ele confere ao seu adversário um papel importante, em especial ao tratar do tema da justiça e do ressentimento. Palavras-chave: Nietzsche, Dühring, ressentimento, vingança, justiça. 
- aos leitores que têm ouvidos eu lembro mais uma vez daquele apóstolo da vingança berlinense Eugen Dühring, que na Alemanha atual faz o uso mais indecoroso e repugnante do bumbum moral: Dühring o primeiro dos fanfarrões da moral que hoje existe, inclusive entre seus iguais, os antisemitas.

\section{Apresentação}

Karl Eugen Dühring ${ }^{2}$ é reconhecidamente uma fonte, um interlocutor e um adversário importante de Nietzsche $^{3}$, em especial nas análises do filósofo sobre a justiça, nas quais, certamente graças a Dühring, os temas da vingança e do ressentimento ganham destaque. De fato, Nietzsche não parece demonstrar interesse pela palavra "ressentiment" antes da leitura do

\footnotetext{
1 GM, III §14. Para as citações das obras de Nietzsche, serão utilizadas siglas já padronizadas seguidas da indicação da parte ou do aforismo, conforme o caso. Em se tratando de anotações pessoais de Nietzsche, será indicado o volume e a página em que o texto se encontra ou na edição crítica (KSA) ou na edição das cartas de Nietzsche (KSB), ambas organizadas por Giorgio Colli e Mazzino Montinari. Para os textos de Nietzsche, embora opte por apresentar uma tradução própria, não deixo de consultar as traduções disponiveis em português, em especial aquelas feitas por Paulo César de Souza, Rubens Torres Filho, Mario da Silva e Andrés Sánchez Pascual (esta última em espanhol). Traduções que recomendo para aqueles leitores que não tem acesso ao texto em alemão do filósofo. Para o caso das obras de Dühring, em função do grande número de citações, também serão apresentadas formas abreviadas seguidas do número da página da edição utilizada por Nietzsche. Também neste caso e no de outros textos que não encontram tradução para o português, apresento uma tradução própria.

2 Dühring nasceu em Berlim no dia 12 de janeiro de 1833 e morreu em Babelsberg em 21 de setembro de 1921. Foi professor na Friedrich-Wilhelms-Universität de Berlim, atual Humboldt-Universität, entre os anos de 1864 a 1921 e ficou conhecido especialmente por suas polêmicas e pelas posições assumidas em temas como o socialismo e 0 antisemitismo.

${ }^{3}$ Conforme demonstra, por exemplo, Aldo Venturelli, que faz uma reconstrução da "relação de Nietzsche com o filósofo de Berlim em seu desenvolvimento e em suas diferentes fases" (VENTURELLI, 2003, p. 204), tendo em vista os textos de Nietzsche e, de modo especial algumas passagens do primeiro livro de Humano, demasiado humano, como é o caso dos aforismos 28, 29, 32, 33, 34, 129, 131, 132, 134, 135 e 140 (VENTURELLI, 2003, p. 209 a 219). Entre outros, também Volker Gerhardt apresenta um estudo sobre essa relação, considerando em especial o texto de Humano, demasiado humano, para o qual aponta Dühring como uma fonte, que forneceria um "modelo" para Nietzsche (GERHARDT, 1983, p. 120). Tendo em vista esses trabalhos e outros sobre a relação entre Nietzsche e Dühring, enfatizamos que nosso interesse nessa relação circunscreve-se ao tema da vingança e do ressentimento, tendo em vista o debate que tem lugar em Para a genealogia da moral.
} 
livro de Dühring $O$ valor da vida. Uma reflexão filosófica ${ }^{4}$ (doravante citado como WL), no qual o termo se encontra ligado à tese do professor de Berlim sobre a origem da justiça. Mesma tese encontrada também em outro livro de Dühring intitulado Curso de filosofia como rigorosa e científica concepção de mundo e configuração de vida (doravante citado apenas como Cursus) de $1875^{5}$. Conforme se pode observar nas anotações deixadas por Nietzsche $^{6}$, esses dois livros despertam nele um grande interesse, sendo o primeiro objeto de uma análise meticulosa, em 1875 (KSA 8, p. 131-185), e ambos citados diversas vezes em textos publicados e em fragmentos póstumos e mencionados, de forma precisa pela questão da vingança e do ressentimento, em Para a genealogia da moral (GM, II, §11).

Conquanto nosso estudo se concentre na discussão de Nietzsche com Dühring de 1887, apresentamos a título de pressuposto de nossa análise, inicialmente, algumas observações sobre os primeiros contatos de Nietzsche com a obra de Dühring; em seguida, fazemos uma exposição sucinta das teses de Dühring tomadas por Nietzsche para serem debatidas especialmente em Para a genealogia da moral; acompanhamos na seqüencia os argumentos de Nietzsche em seu "escrito polêmico" contra as teses de Dühring e; em seguida, a sua crítica, na mesma obra, ao próprio professor de Berlim, tomado por ele, então, como um representante da moral do ressentimento; e finalizamos com algumas observações que ressaltam o modo como Nietzsche se apropria de Dühring em especial em seu livro de 1887.

\section{Os primeiros contatos de Nietzsche com a obra de Dühring}

As primeiras menções de Nietzsche a Dühring aparecem em sua correspondência no ano de 1868, quando o filósofo manifesta o seu

\footnotetext{
4 Trata-se da edição de 1865 do livro cujo título original é Der Werth des Lebens. Eine philosophische Betrachtung. Para estudos da recepção dessa obra, merece atenção o fato de que as edições posteriores, de 1877 e de 1891, foram modificadas e retrabalhadas pelo autor, embora ele afirme que 0 seu conteúdo e os pensamentos fundamentais permanecem inalterados (DÜHRING, 1891, p. III).

5 Título original: Cursus der Philosophie als streng wissenschaftlicher Weltanschauung und Lebensgestaltung. O livro teria sido adquirido por Nietzsche em 21 de abril de 1875 (KSA 14, p. 568).

${ }^{6}$ Às referências de Nietzsche, diretas ou indiretas às obras de Dühring, devem-se acrescentar também os vestígios de leitura e as notas deixados pelo filósofo à margem do seu exemplar do Cursus der Philosophie que se encontra ainda hoje na biblioteca pessoal de Nietzsche em Weimar.
} 
interesse em conhecer o pensamento do renomado professor "o qual [segundo ele] sempre apresentou belos cursos, por exemplo, sobre Schopenhauer e Byron, sobre o pessimismo etc.” (KSB 2, p. 258). Com relação aos escritos de Dühring, as primeiras alusões de Nietzsche aparecem nas suas anotações pessoais do ano de 1875, quando apresenta o propósito de tomar a obra do professor de Berlim, particularmente $O$ valor da vida e o Curso de filosofia (KSA 8, p. 129), como contraponto à influência que recebera de Schopenhauer, tendo em vista uma tentativa de afastamento do antigo mestre (KSA 8, p. 129. Cf.: KSB 2, p. 258). É ao certo em função de tal propósito que Nietzsche faz um estudo detalhado do livro $O$ valor $d a$ vida, naquele mesmo ano, dando origem a um manuscrito de 50 páginas (KSA 8, p. 131-181) com anotações, citações, críticas e um comentário final.

De fato, na introdução de seu livro, Dühring se propõe a avaliar o conflito entre otimismo e pessimismo (WL, p. III), oferecendo a Nietzsche elementos para discutir, por exemplo, a filosofia de Schopenhauer como uma proposição prática de negação da vida (WL, p. 5). Segundo Dühring, um juízo sobre o valor da vida não é lógico, mas absurdo, pois não temos a representação para outras possibilidades diferentes de vida ou de mundo para perguntarmos pelo valor da vida, ou se a disposição geral dos sentidos e dos ânimos seria compatível com o desenvolvimento harmônico da existência, ou se este seria o melhor dos mundos (WL, 1865, p. 9; cf.: KSA 8 , p. 134). Tal análise crítica é corroborada por Nietzsche que acrescenta: "não é possível oferecer qualquer conceito teórico, o qual antecipadamente determine como a vida deveria ser arranjada para ter a nossa aprovação" (KSA 8, p. 133; cf.: WL, p. 10), ressaltando ainda que "o juízo sobre o valor da vida é, dito de forma breve, um afeto - ou uma necessidade da vida ou um aborrecimento da vida" e afirmando, a partir de Dühring, que o ódio a ela é um "movimento da vida que se move contra a própria vida" (KSA 8, p. 133 - 134; cf.: WL, p. 8). Segundo Nietzsche, tendo Dühring como referência, qualquer juízo emitido a partir de tais questões expressaria um “conhecimento impuro" (KSA 8, p. 135), pois conferiria uma medida não propriamente ao objeto avaliado, como se teria no campo da teoria pura, mas àquele que avalia, correspondendo assim, tais juízos, antes, ao campo da prática. Isto não significa, porém, segundo Nietzsche, tomando partido a favor de Schopenhauer neste ponto, que não teríamos direito a tais juízos 
(KSA 8, p. 136), pois, segundo ele, "nós somos a princípio seres ilógicos e, por consequência, também injustos e podemos saber isso!" (KSA 8, p. $136)^{7}$.

Ao concluir sua análise do texto de Dühring, Nietzsche apresenta ainda uma tese sucinta sobre o ressentimento como uma forma de autoconhecimento e autopunição. Para além da proposição "equivocada" (KSA 8, p. 174) de Dühring de que, "fazer do egoísmo (...) a regra dominante das relações humanas é, no fundo, apenas uma aparência e nenhuma verdade duradoura" (WL, p. 186), Nietzsche apresenta uma diferenciação entre um egoísmo "ávido e cego" e um egoísmo, que tem no "amor mais puro" a si mesmo uma forma de desprezo (Verachtung) de si. Tendo em vista esse tipo de amor, Nietzsche chega à ideia de ascese entendida como justiça ${ }^{8}$ aplicada a si mesmo. Essa justiça, possibilitada pelo autoconhecimento, corresponderia a um "sentimento de vingança contra si mesmo", que é experimentado - e praticado como uma ascese - quando alguém "em sua propensão para o pecado" tenha "sofrido bastante de si [e] se ferido de forma assaz" (KSA 8, p. 180). Conforme lembra Marco Brusotti (1997, p. 124), tal concepção, que aproxima Nietzsche de Dühring em 1875, será um dos pontos mais acirrados da crítica do filósofo ao professor de Berlim em $1887^{9}$. Outros sinais da leitura do livro O valor da vida aparecem ainda nos escritos posteriores de Nietzsche, precisamente quando ele se interessa em marcar seu afastamento em relação a Schopenhauer e em buscar novas fontes para sua filosofia, no caso, uma fundamentação científica e materialista, como se verifica, por exemplo, em algumas passagens de Humano, demasiado humano ${ }^{10}$.

\footnotetext{
7 Analisando a correlação entre Nietzsche e Dühring, Marco Brusotti afirma que, embora em parte Nietzsche mantenha-se favorável a Schopenhauer, o fato é que ele acompanha Dühring, por exemplo, quando este reconduz a metafísica em geral à condição de vingança (BRUSOTTI, 1997, p. 662) e também quando concebe o pensamento do filósofo de Frankfurt como uma "metafísica da vingança" (BRUSOTTI, 1997, p. 570 - nota 44).

${ }^{8} \mathrm{O}$ termo "justiça" é entendido, aqui, no sentido conferido a ele por Dühring, como ressentimento e sede de vingança.

9 Uma comparação entre essa concepção de ascese entendida como "vingança contra si mesmo" e a que se encontra na terceira dissertação de Para a genealogia da moral, associada ao "ideal ascético" e ao "sacerdote ascético", é apresentada por Marco Brusotti em seu artigo "Ressentimento e vontade de nada" (BRUSOTTI, 2000, p. 25-28).

${ }^{10}$ Além das passagens já mencionadas de Humano, demasiado humano (cf. acima, nota 3) em que se constata a presença de Dühring nos escritos de Nietzsche, tem-se também algumas variações da relação de Nietzsche com as teses de Dühring, que evidenciam a crítica do filósofo ao professor de
} 
Por sua vez, o Curso de filosofia, embora tenha sua importância assegurada quanto à explicitação do pensamento de Dühring, não apresenta uma variação significativa em relação à tese sobre a origem da justiça a partir da vingança e do ressentimento ${ }^{11}$. Da parte de Nietzsche, em comparação à obra $O$ valor da vida, pode-se mesmo dizer que o Curso recebeu uma atenção menor ${ }^{12}$, sendo lido apenas posteriormente pelo filósofo e, de resto, como "motivo de riso"13. Da leitura do Curso restam os vestígios deixados no exemplar que ainda hoje se encontra na biblioteca pessoal de Nietzsche, em Weimar, e também os sinais observados em fragmentos do ano de $1883^{14}$, além das referências feitas a ele, juntamente com $O$ valor da vida, em Para a genealogia da moral. Embora nem sempre se possa precisar nos apontamentos de Nietzsche as nuances que indicam o uso de uma ou de outra dessas duas obras de Dühring, é possível observar uma mudança nas citações e comentários a partir do início da década de 80 . Se até esse momento predominavam as referências à primeira, a partir daí, observa-se, nas referências a Dühring, concomitante às características da primeira, também traços peculiares à segunda, como é o caso do recurso mais acentuado à natureza (Naturnotwendgkeit - Cursus, p. 239), da correlação entre a mecânica cósmica e a do corpo (HKSA 10, p. 270) e da ideia do ressentimento como uma reação mecânica (cf. GM, III, §15).

De Dühring, além desses dois livros, Nietzsche teria lido também: Causa, vida e inimigos (Sache, Leben und Feinde), uma autobiografia do professor de Berlim datada de 1882. É essa obra que Nietzsche tem em mente, por exemplo, quando escreve em seus apontamentos pessoais que Dühring teria "esclarecido sobre sua vida, sem esquecer nenhum dissabor e nenhuma ofensa desde a infância" (HKSA 11, p. 251) e também, ao certo,

\footnotetext{
Berlim num sentido que será mais conhecido em Para a genealogia da moral. Elas se encontram, segundo Aldo Venturelli, por exemplo, no aforismo 92 do mesmo primeiro livro de Humano e no aforismo 33 de $O$ andarilho e sua sombra (VENTURELLI, 2003, p. 229).

${ }^{11}$ A variação verificada no Cursus em relação ao livro $O$ valor da vida, conforme veremos, diz respeito especialmente ao fundamento das ações humanas, que passam a ser determinadas de forma bem mais acentuada, pela natureza e por forças mecânicas.

12 Cf. VENTURELLI, p. 220.

${ }^{13}$ A leitura do Curso ocorre entre 1875, ano em que Nietzsche apresenta o propósito de lê-lo, e 1881, ano da carta endereçada à irmã solicitando a ela o envio do exemplar do livro que se encontra em sua estante. É nessa carta que se lê o comentário de que aquela obra seria, para ele, "motivo de riso" (KSB 6, p. 99).

14 VENTURELLI, 2003, p. 222, nota 226. Referência à KSA 10, p. 270.
} 
quando refere-se a Dühring pelo fato de ele voltar-se sobre si mesmo (onanismo) na seção 14 da terceira dissertação de Para a genealogia da moral.

\section{A tese de Dühring sobre a origem da justiça e as primeiras críticas de Nietzsche}

Segundo Dühring, a ideia de justiça surge na consciência do homem como a representação de um sentimento. Sua origem, porquanto, não está ligada à consciência abstrata, mas a "um impulso" (WL, p. 20), o qual seria, mais precisamente, a um "afeto reativo" (WL, p. 21) ou a um "sentimento reativo" (WL, p. 71), pois corresponderia a uma resposta a um estímulo anterior, como é o caso, por exemplo, de uma agressão. Desta forma, a justiça se caracterizaria, segundo ele, como um "impulso de retribuição" (Vergeltungstrieb), que se traduziria pela palavra "vingança" (WL, p. 21) $)^{15}$. Em resumo, a palavra "vingança" resolveria para Dühring o enigma do sentimento de justiça (Rechtsgefühl) (Cursus, p. 226), o qual seria, "essencialmente, um ressentimento" (WL, p. 219).

A justiça corresponderia, assim, a um "um sentimento para trás (Rückempfindung)", designado pelo termo "ressentimento", do qual derivaria "uma necessidade de retribuição (Vergeltungsbedürfniss)" (Cursus, p. 224), seguida da vingança propriamente dita como uma forma de descarga daquele afeto. Segundo o professor de Berlim, aquele (re)sentimento tem lugar quando um indivíduo é vítima de um "mau maior" (WL, p. 175), de uma crueldade injustificada e injusta, ou seja, de uma agressão que não teria sido motivada por uma agressão anterior. Tal agressão confere àquele que a sofreu, segundo Dühring, o direito de voltarse contra o agressor e de descarregar nele o sentimento que inicialmente fora "voltado para trás". Assim, a justiça, entendida como uma reação (Rückwirkung), como o exercício daquele direito de voltar-se contra o

\footnotetext{
15 Seguindo a argumentação de Dühring em $O$ valor da vida, tem-se que a justiça não estaria fundamentada em qualquer forma primária de natureza anterior às relações humanas, originando-se a partir da convivência dos homens entre si, quando então são conhecidos sentimentos como o de vingança, ódio e compaixão (WL, §23), sentimentos que não existiriam caso fosse considerada a hipótese de um homem viver sozinho sobre a terra. Essa tese, contudo, sofre alguma variação no livro Curso de filosofia, no qual Dühring dará maior ênfase à ideia de uma retribuição como ação mecânica e ao movimento de autoconservação (Selbsterhaltung) como um "arranjo da natureza" (Cursus, p. 224).
} 
agressor, corresponderia a uma violência legítima (Cursus, p. 212) por parte daquele que sofreu o dano e, do ponto de vista daquele que realizou uma agressão primária, ela corresponderia a uma "colheita" (Cursus, p. 217), pois ele obteria, com ela, apenas as consequências de sua ação.

Ao estabelecer aquele "mau maior" como o ato primário que daria origem ao sentimento de justiça, e ao fazê-lo tendo em vista o campo das relações humanas, Dühring teria, conforme assinala Nietzsche em 1875 (KSA 8, p. 178), se afastado da aparente necessidade, tão comum aos filósofos, de buscar um fundamento para a justiça e para a moral na natureza ou em algum forma de metafísica. Longe de tal necessidade, o professor de Berlim diferencia o justo do injusto, o bom do mau, "identificando qual é o lado que padece" (WL, p. 72). Tal procedimento, contudo, não colocaria as suas reflexões no "caminho certo" (GM, I, §4), tendo em vista as análises de Nietzsche de 1887, por dois motivos. Primeiro, porque não se poderia falar em ações humanas originariamente más, mesmo se for considerado, como faz Dühring, o lado que padece; e segundo, porque faltaria às reflexões do renomado professor justamente 0 "espírito histórico" (GM, I, §2) que permitiria a ele observar a "transformação conceitual" 16 à qual tais juízos foram submetidos.

Em relação ao primeiro motivo, cabe lembrar que, para Nietzsche, ““justo' e 'injusto' existem apenas a partir da instituição da lei (e não a partir do ato ofensivo, como quer Dühring)". Para ele, "em si, ofender, violentar, explorar, destruir não pode naturalmente ser algo "injusto" uma vez que "nas suas funções básicas, a vida atua ofendendo, violentando, explorando, destruindo..." (GM, II, §11). Em relação ao segundo motivo, Nietzsche observa que Dühring toma uma concepção tardia, que confere à justiça o papel de conter o agressor, de opor-se à luta egoísta do homem pela existência (Cursus, p. 246), de inibir a expansão de suas forças naturais (WL, p. 93) e de restabelecer a igualdade entre os homens, e a coloca no início da justiça. Assim, do mesmo modo que os genealogistas da moral que “identificam uma 'finalidade' qualquer no castigo, por exemplo, a vingança ou a intimidação, e então a colocam inocentemente essa finalidade no início, como causa da origem [causa fiendi] do castigo" (GM, II, §12),

${ }^{16} \mathrm{GM}, \mathrm{I}$, §4. A respeito da noção de "transformação conceitual" conferir: PASCHOAL, 2009, p. 17-30. 
também Dühring ${ }^{17}$ toma uma "forma tardia do julgamento e do raciocínio humanos" e a desloca para o início. Desse modo, também ele produz o equívoco típico de quem não possui "conhecimento do passado" e que, desprovido de um "instinto histórico" (GM, II, §4), termina por desconsiderar "a longa história de variedade de formas" (GM, II, §3) que se encontra atrás das coisas, conceitos e instituições, como é o caso da justiça.

\section{A contraposição de Nietzsche à tese de Dühring sobre a origem da justiça}

Particularmente em relação ao tema da origem da justiça, associado à noção de ressentimento, depois de 1875 e da seção 92 de Humano, demasiado humano ele volta a ocupar um lugar de destaque num texto de Nietzsche apenas no ano de $1887^{18}$, em Para a Genealogia da moral ${ }^{19}$. É nesse livro que encontramos a crítica de Nietzsche às teses do professor de Berlim sobre a justiça e também ao próprio Dühring, tomado pelo filósofo como uma expressão da própria moral do ressentimento.

Seguindo um caminho diferente daquele trilhado por Dühring, Nietzsche afirma em Para a genealogia da moral que a justiça não tem sua origem num sentimento reativo e nem cumpre um mero papel de inibição das forças agressivas do homem, como se ela tivesse sido criada em contraposição à própria vida. Para Nietzsche, os estados de direito não se constituem para atender a uma suposta propensão mecânica de “autopreservação", conforme propõe Dühring (WL, p. 42 e Cursus, p. 224), ou ainda como "um meio contra toda luta" (GM, II, §11). Para o filósofo, os estados de direito, mesmo entendidos como "estados de exceção", não são

\footnotetext{
17 É interessante ressaltar que também Dühring se ocupa das raízes do comportamento moral do homem, especialmente no capítulo intitulado "Costume, justiça e humanidade nobre" (Sitte, Gerechtigkeit und edlere Menschlichkeit) de seu livro Cursus der Philosophie, de 1875.

18 Dühring, nesse momento, já não desfruta do breve sucesso que teve nos anos anteriores quando propalava sua "Filosofia da efetividade" (Wirklichkeitsphilosophie). A partir de 1877, período em que publica sua autobiografia e seus escritos anti-semitas, encontramos um Dühring marcadamente decadente (Cf. VENTURELLI, 2003, p. 205 e p. 223, nota 228). É de se notar também que a utilização do professor de Berlim com o intuito de afastar-se de seu antigo mestre, apontada nos textos de $1875 \mathrm{e}$ dos anos seguintes, não interessa mais a Nietzsche neste momento.

${ }^{19}$ Conforme veremos, a crítica a Dühring aparece também em outros textos do período da Genealogia, como é o caso, para nos mantermos apenas no âmbito das obras publicadas, da seção "Das Tarântulas", de Assim falou Zaratustra, onde aparece de forma indireta e do aforismo 204 de Além de Bem e Mal, onde o professor de Berlim é mencionado diretamente.
} 
contrários ao princípio geral de expansão da vida e não visam conter o poder no homem. Ao contrário, eles surgem como meios para se produzir "maiores unidades de poder" (GM, II, §11).

Da mesma forma, contra o "clichê comunista de Dühring", Nietzsche toma por princípio que o direito é criado pelos fortes, ativos, espontâneos, agressivos, e não pelos "homens reativos" (GM, II, §11). Desde seus primórdios a justiça se constitui, segundo o filósofo, como a "boa vontade entre os homens de poder aproximadamente igual, de se colocarem de acordo entre si, de se 'entenderem' novamente por meio de um acordo - e, com relação aos mais fracos, de forçar a um compromisso" (GM, II, $\S 8)^{20}$. Ela se originaria, portanto, entre homens que possuem poder em abundância, um poder "sobre si mesmos e sobre o destino" (GM, II, §2) e que reconhecem tal poder, estabelecendo em relação aos demais um pathos de distância. $\mathrm{O}$ mesmo pathos a partir do qual tais homens conferem nomes, criam valores e plasmam formas, como é próprio a organizadores natos, àqueles, por exemplo, que criam o "Estado" (GM, II, §17).

Avançando em sua argumentação, Nietzsche afirma que em toda parte onde a justiça é exercida, onde ela é mantida, o que se vê "é um poder mais forte que busca meios para por fim, entre aqueles que em relação a eles são mais fracos (sejam eles grupos, sejam eles indivíduos), ao insensato furor do ressentimento, em parte retirando das mãos da vingança o objeto do ressentimento, em parte colocando no lugar da vingança, por sua vez, a luta contra os inimigos da paz e da ordem, em parte inventando, propondo e em algumas circunstâncias impondo acordos, em parte elevando à categoria de norma certos equivalentes de danos, com os quais, desde então e de uma vez por todas, o ressentimento é expulso" (GM, II, §11). Mais ainda, para o filósofo, com o fortalecimento do poder da comunidade, a justiça, que em seu início se pautou no cânon "cada coisa tem um preço; tudo pode ser pago", afasta-se cada vez mais das exigências de retribuição próprias de uma comunidade fraca e que se sente ameaçada. Segundo Nietzsche, o aumento do poder da comunidade e a consciência de tal poder pelos membros dessa comunidade são acompanhados da imposição de castigos

\footnotetext{
20 Já em Humano, demasiado humano, Nietzsche afirma que "a troca é o caráter inicial da justiça" e que "a retribuição e o intercâmbio se fazem sob o pressuposto de um poderio mais ou menos igual" $(\mathrm{HH}$, $\S 92)$.
} 
mais brandos e impessoais e da busca por meios de se "acomodar a questão" e de se evitar "maior participação e inquietação". O objetivo tornase, então, desviar "os sentimentos dos seus subordinados do dano imediato" causado a eles e assim conseguir "o oposto do que deseja a vingança, a qual enxerga e faz valer apenas o ponto de vista do prejudicado" (GM, II, §11). Nesse estágio de sua evolução, essa comunidade assume o dever de proteger o criminoso justamente contra a sede de vingança daquele que fora lesado e de julgá-lo com a imparcialidade que não seria encontrada em um juiz que tivesse nos olhos o ódio e a sede de vingança. Em seu ponto culminante ${ }^{21}$, com a abundância de poder e com a consciência de tal abundância, essa comunidade poderia mesmo se permitir o seu mais "nobre luxo" de, num ato de "graça" (Gnade), deixar "livres os insolventes" (GM, II, §10) ${ }^{22}$. Em resumo, as observações de Nietzsche sobre a evolução do direito penal indicam o oposto daquilo que fora preconizado por Dühring. Para ele, nem em sua origem, nem no seu ápice a justiça seria a expressão de forças reativas ou se justificaria a partir delas, como seria o caso se fosse aceita a hipótese de que ela existiria apenas como um canal pelo qual se extravasaria o sentimento de vingança daquele que sofreu uma agressão. "Como se [ela] fosse apenas um desenvolvimento do sentimento de estar ferido" (GM, II, $\S 11)$.

Parte integrante da argumentação de Nietzsche, em especial ao tratar da origem da justiça, a noção de castigo como retribuição, ou pagamento (Vergeltung), encontrada na segunda dissertação da Genealogia (GM, II, $\S 4)$, poderia ser tomada, numa leitura apressada ao certo, como sendo correlata àquela ideia de um impulso à retribuição (Vergeltungstrieb) encontrada nos escritos de Dühring e, portanto, como sinônimo de vingança. Conforme vimos, Nietzsche identifica no início da justiça a presença do cânon "cada coisa tem um preço; tudo pode ser pago", assinalando o parentesco entre a justiça e as relações básicas do comércio

21 a ápice da justiça não corresponde a um ponto de chegada necessário ao qual ela seria conduzida com o transcorrer do tempo. Trata-se antes de uma projeção de Nietzsche, de algo que pode ser notado em parte em certos estados particulares, mas que, de resto, se mantém como uma espécie de utopia. Para Nietzsche, o processo histórico não é um jogo fechado, mas aberto, em que forças buscam "assenhorar-se e subjugar", impondo sempre novas interpretações, ajustes, sentidos e utilidades (GM, II, $\S 12)$.

${ }^{22} \mathrm{O}$ que pode ser chamado de autosuperação da justiça, conforme discorre Oswaldo Giacoia em seu artigo "A Auto supressão como catástrofe da consciência moral" (GIACOIA, 2010). 
como a compra, a venda, a troca e a "dívida" ${ }^{23}$ (GM, II, §4), ao ponto de apresentar a hipótese de que seria possível correlacionar o substantivo homem (Mensh) com o verbo medir (messen), caracterizando assim, etimologicamente, o homem como o animal que mede, que atribui valores e, por decorrência, o animal que estabelece equivalências e formas de retribuição e de pagamento (Vergeltung).

Neste ponto, caberia lembrar novamente que a vingança veiculada por Dühring corresponde a uma forma "tardia do julgamento e do raciocínio humanos", segundo Nietzsche, e que a ideia de pagamento (Vergeltung) encontrada na Genealogia da moral não é apenas anterior como é também mais abrangente do que o impulso à retribuição (Vergeltungstrieb) presente nos escritos de Dühring. Neste sentido, vale observar que Dühring só se interessa por aquele impulso no seu "grau mais elevado", ou seja, como "vingança" (WL, p. 219) e que é somente nesse grau que ele concebe aquele impulso como fundamento da justiça. Assim, o professor de Berlim descarta de sua teoria qualquer possibilidade de retribuição que se traduziria, por exemplo, como o pagamento do bem com o bem ou como alguma forma de gratidão (Dankbarkeit - WL, p. 225-226; Cursus, p. 201). Para ele, a ampliação da abrangência de sua hipótese levaria à perda da sua especificidade, que consiste em tomar como pressuposto da justiça apenas o sentimento de desagravo que produziria aquele impulso de retribuição capaz de levar o homem a perseguir seu detrator até seu túmulo "com o desagravo da injustiça nos olhos" (WL, p. 226; cf.: Cursus, p. 204). Por sua vez, a ideia de pagamento (Vergeltung) que se tem na segunda dissertação da Genealogia, não envolve apenas aquilo que Dühring chama de retribuição em seu "grau mais elevado", que seria a vingança. No texto de Nietzsche, conquanto se tenha claramente noção de uma equivalência entre "dano e dor" e também de que o castigo é aplicado ao delinquente na medida do dano causado, deve-se observar que tal castigo não corresponde, em épocas primitivas, à simples imputação de culpa. Para o filósofo, "durante o mais longo período da história humana, não se castigou porque se atribuiu

\footnotetext{
23 O termo "dívida", destacado entre aspas por Nietzsche nessa passagem, corresponde ao alemão "Schuld", que significa tanto "dívida" quanto "culpa". Um termo que possui um uso muito acentuado no cristianismo, e que, contudo, neste ponto, Nietzsche pretende que seja tomado no sentido "bem material", pois somente mais adiante, por exemplo, na seção 20 da terceira dissertação, o filósofo fará a correlação entre "dívida", ou, "culpa" e "pecado".
} 
responsabilidade ao delinquente (Übelanstifter) por seu ato, portanto, não pelo pressuposto de que apenas o culpado deveria ser castigado" (GM, II, $\S 4)$. Seguindo ainda o texto de Nietzsche é possível observar que o castigo mesmo sendo entendido como equivalência não se aplica exclusivamente à retribuição por danos sofridos ${ }^{24}$, como se tem na tese de Dühring, mas também, como pagamento por benefícios adquiridos, conforme se observa, por exemplo, na rel,ação de dívida das antigas sociedades tribais com seus ancestrais e, depois, com seus deuses. Nesse caso, trata-se de uma dívida que exige sacrifícios não por perdas, mas em função das vitórias e da prosperidade daquela tribo (GM, II, §19), algo que no seu extremo pode ser entendido como o pagamento por um bem ou, até mesmo, como um ato de gratidão (Dankbarkeit).

Outro aspecto relevante na correlação entre as teses de Nietzsche e de Dühring sobre a origem e a finalidade da justiça, diz respeito à noção de igualdade (Gleichgewicht), que se encontra, em certa medida, presente nos dois livros de Dühring e, no caso de Nietzsche, especialmente no aforismo 92 de Humano, demasiado humano ${ }^{25}$ e na segunda dissertação da Genealogia da moral.

A noção de igualdade presente nos escritos de Dühring como um pressuposto da justiça, especialmente na obra $O$ valor $d a$ vida ${ }^{26}$ é um conceito complexo e que desperta interesse em Nietzsche. Para Dühring, a igualdade não corresponde, por exemplo, a uma igualdade de almas ${ }^{27}$, ou um "conceito elevado" (WL, p. 22), como um princípio metafísico, ou ainda a alguma medida pré-estabelecida entre os homens que se traduziria, por exemplo, numa igualdade de capacidades (WL, p. 32). De fato, próxima à ideia que vamos encontrar nos escritos de Nietzsche, ela é, antes, uma disposição de

\footnotetext{
${ }^{24}$ Assinalamos aqui a noção de castigo entendida como uma forma de pagamento. Porém, para além dessa noção, o castigo compreende, na argumentação de Nietzsche, várias outras formas e finalidades como, por exemplo, a descarga de uma ira, a reparação de um dano, festa etc. (Conferir outros exemplos em GM, II, §13).

${ }^{25} \mathrm{Em} 1878$, conforme assinala Volker Gerhardt, a tese de Nietzsche estaria alinhada à de Dühring, que seria uma importante fonte para Nietzsche naquele momento, quando o filósofo buscava estabelecer de forma científica a proveniência do direito e da moral (GERHARDT, 1983, p. 118).

${ }^{26}$ A referência, nesse caso, de forma específica ao livro $O$ valor da vida, deve-se ao fato de que é da concepção explicitada especialmente ali, de uma igualdade medida no confronto, que se tem a possibilidade de discussão com Nietzsche. Conforme já mencionamos anteriormente, tais teses, ao serem expostas no Cursus aproximam-se mais de uma fundamentação dada pela natureza.

${ }^{27}$ Conforme ressalta Nietzsche em seu comentário ao livro de Dühring em 1875 (KSA 8, p. 141).
} 
forças que se colocam umas diante das outras e, nesse momento, medem-se (WL, p. 22 e 41). Tal ideia, que é transcrita por Nietzsche, em 1875, como "direitos iguais apenas em condições de igualdade de poder, portanto, entre iguais" (KSA 8, p. 150), é veiculada também, em parte, pelo filósofo quando trata do estabelecimento de um acordo entre homens de "poder aproximadamente igual" no texto de Humano, demasiado humano (92) e na Genealogia da moral (GM, II, $\S 4)^{28}$.

Nesses dois textos ${ }^{29}$, como forma de ampliar a noção de igualdade encontrada nos escritos de Dühring, Nietzsche a correlaciona com o comércio, onde a igualdade se vê envolvida num jogo de medidas, pesos e variações de valores conforme, por exemplo, algo esteja sendo comprado ou vendido (Cf.: HH, II, AS, §22. Cf. também: GERHARDT, 1983, p. 124). Desta forma Nietzsche salienta o caráter variável que possui o termo "igualdade" (Gleichgewicht), o qual literalmente significa "pesos semelhantes" e é construído a partir do radical "wicht[ig]", que permite, no caso, a correlação ente peso (gewicht) e algo a que se atribui importância (wichtig), portanto, algo contextualizado e não fixo.

\footnotetext{
${ }^{28}$ Não se deve perder de vista ainda no que se refere à influência de Dühring, contudo, que a ideia de certa igualdade de forças é um pressuposto da boa disputa entre os gregos, caberia lembrar que essa ideia encontra-se nos escritos de Nietzsche antes mesmo de sua leitura de Dühring, por exemplo, do quinto dos Cinco prefácios para cinco livros não escritos, intitulado "A disputa de Homero". Ali a disputa pressupõe um "poder aproximadamente igual", pois não poderia ocorrer nos extremos em que se teria a submissão completa ou em que um oponente já não encontraria adversário (KSA 1, p. 783ss).

${ }_{29}$ Cabe notar, de forma breve, que embora os dois textos citados de Nietzsche - de HH e da GM apresentem aspectos semelhantes no tocante à origem da justiça, como é o caso, por exemplo, da afirmação de que ela tem sua origem entre homens de "poder aproximadamente igual" (HH I, §92; GM, II, §4) e também de que "o caráter da troca é o caráter inicial da justiça" (HH, I, §92; GM, II, §4), eles não são propriamente idênticos. Dentre as dissimetrias que podem ser apontadas numa rápida comparação entre ambos, destaca-se: a presença ainda no texto de 1878 da ideia de vingança na origem da justiça, um dos sinais mais claros da influência de Dühring sobre Nietzsche nesse momento e um dos pontos mais duramente criticados por Nietzsche contra Dühring em 1887; a associação, em 1878, entre a ideia de justiça e a de "autopreservação" (Selbsterhaltung), outro aspecto que aproximaria novamente o texto de Humano das teses de Dühring ao mesmo tempo em que o afasta do próprio texto de Nietzsche de 1887, quando, para o filósofo, a justiça não se constituirá para produzir equilíbrio ou autopreservação, mas "para criar maiores unidades de poder" (GM, II, §11); o papel atribuído ao esquecimento, que possuiria, em 1878, um papel decisivo na origem da moral e da justiça, enquanto em 1887 não só é abandonado por Nietzsche, como é apontado como um dos equívocos dos genealogistas da moral (GM, I, §1) e como um argumento a favor da tese de que os juízos de valor moral e também a justiça seriam produtos dos fracos. Assim, conquanto existam semelhanças entre os dois textos, não se poderia tomálos desconsiderando as variações entre ambos e menos ainda adotar a ideia de que Nietzsche tomaria 0 "modelo" de Dühring, como afirma Volker Gerhardt referindo-se ao texto de 1878, (GERHARDT, 1983, p. 120) e o utilizaria em toda a sua obra, em especial para a sua Genealogia.
} 
Particularmente em Para a genealogia da moral, conquanto se mantenha a ideia de "uma certa igualdade" entre alguns dos personagens que se encontram na origem da justiça, é interessante notar que mesmo essa noção não exclui a ideia de hierarquia, por mais que isto possa parecer paradoxal. No livro de 1887, o filósofo não apenas acentua a ideia de que na origem da justiça encontram-se homens de poder aproximadamente e não exatamente igual, aspecto que o manteria no limiar do "modelo" de Dühring, mas também deixa claro também que a justiça criada por tais homens não se refere apenas a eles. Ou seja, ela não se aplica apenas àqueles que possuem equivalência de poder $^{30}$, estabelecendo, por exemplo, um acordo entre eles, mas também, conforme vimos anteriormente, àqueles que não possuem a força suficiente para manter a palavra (GM, II, §2) e que necessitam, portanto, de uma medida ${ }^{31}$.

Por fim, para apontar o principal ponto de ruptura de Nietzsche com Dühring nesse aspecto, em 1887, vale observar que o direito, segundo Nietzsche, especialmente em 1887, não tem como função restabelecer uma igualdade rompida por meio de uma crueldade inicial, como se tem em Dühring (WL, p. 95). Em especial, portanto, a igualdade para Nietzsche não se apresenta como uma meta em função da qual se criaria e se exerceria a justiça. O estabelecimento da igualdade como uma meta se faz, segundo Nietzsche, pelos "pregadores da igualdade", entre os quais, um dos mais estridentes é Dühring (ZA, Das tarântulas; GM, III, §14). Este, contudo, não é um dos pontos-chave apenas da contraposição de Nietzsche às teses de Dühring, mas da sua contraposição ao próprio Dühring, cujo "o clichê comunista" e propensão "contra toda luta" (GM, II, §11) teria por meta a autodiminuição do homem e a exclusão do diferente, especialmente do tipo mais elevado de homem.

\section{Dühring: uma poderosa lente de aumento}

Ao se tomar a contraposição de Nietzsche não a uma ideia, mas ao

\footnotetext{
30 Neste sentido, em relação ao texto da Genealogia da moral, dificilmente se poderia falar de um "princípio da igualdade cujo modelo adviria de Dühring" (GERHARDT, 1983, p. 119).

${ }^{31}$ Diferentemente também das teses que atribuem a origem da justiça a um contrato ou de uma espécie de associação de homens entre si, para Nietzsche ela se origina pela imposição de formas e medidas por aqueles que têm maior poder, de um modo semelhante ao verificado, por exemplo, na criação do Estado (GM, II, §17).
} 
seu autor, quando ganha relevo em seu texto traços pessoais de seus adversários, alguns pontos devem ser observados previamente para não se confundir uma estratégia argumentativa com alguma forma de leviandade. Alguns desses pontos são explicitados por Nietzsche ao comentar um dos ataques mais duros que dirige a um de seus contemporâneos (EH, Por que sou tão sábio, §7), David Strauss, em 1873, por meio de sua Primeira Consideração Extemporânea. A observação desse caso particular permite, ao certo, entender, ao menos em parte, esse tipo de estratégia de Nietzsche e por extensão, a sua ofensiva contra Dühring.

São quatro os pontos que caracterizam o que Nietzsche denomina como seu modo próprio de fazer guerra. Primeiro: ele ataca apenas "causas vitoriosas". No caso, conforme já foi mencionado anteriormente, no momento em que Nietzsche escreve sua Genealogia, Dühring encontra-se em uma fase de decadência. Contudo, e isto seria o mais importante, a causa expressa por ele, de um apequenamento do homem por meio da cultura e da moral, continua sendo vitoriosa na Alemanha do final do século, no entender de Nietzsche. Segundo: ele ataca "somente causas em que não encontraria aliados". É notório que Dühring é alvo de várias polêmicas, entre elas a mais conhecida é a crítica dirigida contra ele por Friedrich Engels $^{32}$. Contudo, isto não significa que Nietzsche tenha aliados em sua causa, a qual tem como foco os efeitos de certa concepção de moral, de justiça e de cultura sobre o homem. Terceiro: Nietzsche afirma que nunca ataca pessoas, mas que se serve "de uma pessoa como uma forte lente de

32 Trata-se do conhecido material elaborado entre 1876 e 1877, o Anti-Dühring, que veio a público inicialmente em partes no Vorwärts (Avante), jornal do Partido Social Democrata Alemão, entre 3 de janeiro de 1877 e 7 de julho de 1878 e, como livro, em 1878. Tendo em vista em especial essa crítica de Engels, cabe assinalar que não há uma relação direta dela com a crítica de Nietzsche a Dühring. 0 motivo desta dissonância, além dos interesses divergentes de ambos, pode ser apontado nos livros de Dühring tomados para estudo e nas partes focadas por cada um. Enquanto Nietzsche se ocupa principalmente do livro $O$ valor da vida, acrescentando à leitura desse algumas impressões colhidas do livro Curso de filosofia, Engels tem em mãos para a sua crítica o Curso de Filosofia, o Curso de Economia Política e Social e a História Crítica da Economia Política e do Socialismo (ENGELS, 1988, p. 237). Assim, embora Engels manifeste interesse especial pela primeira obra, o fato é que a coincidência restringe-se a um livro e, mesmo neste caso, a atenção volta-se para pontos diferentes, pois, Nietzsche ocupa-se principalmente com as questões relativas à moral e à justiça, temas que não despertam 0 interesse de Engels na sua análise do texto de Dühring (1988, p. 285). Talvez um item que poderia ser objeto de uma análise comparativa entre as duas críticas seja a coincidência no que se refere ao papel do tempo sobre os fatos e as coisas. Como Nietzsche, Engels critica Dühring em função de sua pretensão de universalidade em suprimir a moral "às leis do tempo e às reais mudanças" (ENGELS, 1988, p. 295). 
aumento com a qual se pode tornar visível um estado de miséria geral, porém, dissimulado, pouco palpável (...)". Independentemente, portanto, da indisposição pessoal de Nietzsche em relação a Dühring, verificada, por exemplo, em sua correspondência, especialmente quando ele vê o seu Zaratustra associado a antisemitas, entre os quais, destaca-se o professor de Berlim (KSB 7, p. 117-118 e 120 e KSB 8, p. 51) $)^{33}$, o ataque a Dühring cumpre um papel estratégico de tornar visível um quadro geral de miséria, ao mesmo tempo em que permite ao filósofo de Naumburg posicionar-se, em termos teóricos e práticos, nesse quadro. Quarto: em consonância com o item anterior, Nietzsche afirma que ataca "somente coisas de que está excluída qualquer diferença pessoal” (EH, Porque sou tão Sábio, §7). Dühring é, neste sentido, impessoal, um instrumento, uma ferramenta e é tomado por sua utilidade na construção argumentativa de Nietzsche, como parte de uma estratégia utilizada por ele em sua crítica à moral.

Tendo em vista esses pontos, é possível identificar dois enfoques na crítica de Nietzsche a Dühring posterior a Assim falou Zaratustra. O primeiro corresponde à indicação do professor de Berlim como exemplo da decadência cultural alemã ${ }^{34}$ e como expressão de um tipo de filosofia ${ }^{35}$ que estaria na "moda" (ABM, §204 e KSA 11, 252) na Alemanha daquele período. O segundo, diz respeito à associação de Dühring com um projeto de autodiminuição do homem e de negação da vida, algo próximo ao que o próprio Dühring criticava em Schopenhauer em 1865.

Nos textos e apontamentos que correspondem ao primeiro enfoque da crítica de Nietzsche, o nome de Dühring será encontrado em associação a uma filosofia caracterizada pelo otimismo e pela auto-satisfação da cultura alemã consigo mesma, de modo semelhante ao que se tem com outros

\footnotetext{
${ }^{33} \mathrm{~A}$ irritação de Nietzsche com os antisemitas e o seu incômodo com o fato de que o seu nome possa ser relacionado a essa faç̧ão, da qual Dühring é um representante manifesto, torna-se explícita em uma carta dirigida à sua mãe em 29 de dezembro de 1887, onde escreve: "Numa sequência, este partido [antisemita] colocou a perder para mim meu editor, minha cátedra, minha irmã, meus amigos - nada me incomoda mais do que ver o nome Nietzsche utilizado em associação com antisemitas como E. Dühring (...). (KSB 8, p. 216-217). Cf. também: KOECHE, 1994, p. 171, nota 82.

${ }^{34}$ Cf.: OTTMANN, H. Philosophie und Politik bei Nietzsche, p. 31 e especialmente sobre Dühring: p. 33ss.

${ }^{35}$ Nesses casos, para Nietzsche, a palavra "filosofia" estaria sendo mau empregada (KSA 13, p. 546).
} 
nomes tais como: David Strauss ${ }^{36}$, Eduard von Hartmann, Richard Wagner e Philipp Mainländer, sem deixar de mencionar o de Richard Wagner.

O termo "moda", que poderia ser associado a vários desses nomes, remete à ideia de "convenção" e também de algo que seria "novo" (KSA 7, p. 687), admirado e, entretanto, condenado ao rápido esquecimento (ABM, §204). Ele expressa ainda o modo como "a evidente autosatisfação de um indivíduo com sua forma incita à imitação e cria pouco a pouco a forma de muitos" (HH, II, §209). O termo "moda" designa, portanto, um modelo, e em especial neste caso, um modelo de autosatisfação a ser imitado e, assim, já corresponde a uma oposição ao indivíduo (ao ego) e a uma afirmação daquilo que se torna comum ao conjunto dos homens. A palavra "moda" é associada por Nietzsche também ao termo "moderno", como se tem no aforismo 99 do segundo volume de Humano, demasiado humano, em que o termo expressa "nosso moderno mundo e efetividade" em oposição a uma "grande alma", a um espírito elevado e a tudo o que estaria associado à "elevação humana" (HH, II, §99), aspectos que Nietzsche associa ao mundo antigo.

Nessa cultura moderna, ganha destaque justamente um tipo de intelectual que se autoglorifica, o "erudito cultivado", influente nos meios universitários e que pretende corresponder ao que designaria, então, a palavra "filósofo". Um termo que, segundo Nietzsche, em associação a Dühring corresponde a um equívoco (HKSA 13, p. 546) e que, em associação, também com Philipp Mainländer e Eduard von Hartmann, corresponderia à fórmula "um 'infinito para traz"” (KSA 11, p. 252).

Denominando-os "leões de Berlim", Nietzsche aponta Hartmann e Dühring como "representantes da filosofia de hoje", os quais, "graças à moda, são tão admirados quanto esquecidos" (ABM, §204). Dühring em particular é tomado pelo filósofo como exemplo de superficialidade e de corrupção (KSA 11, p. 293), um produto da cultura alemã posterior a Bismark $^{37}$, a qual corresponderia a uma forma de "barbárie" (KSA 10, p.

\footnotetext{
${ }^{36}$ A Primeira Consideração Extemporânea: David Strauss o confessor e o escritor é um exemplo do modo como Nietzsche se posiciona criticamente contra tal fenômeno, descrito por ele, na ocasião, como um "filisteísmo cultural", que em sua época "tornou-se sistemático e foi elevado à condição de dominante" (CE, I, §2).

${ }^{37} \mathrm{Na}$ Primeira Extemporânea Nietzsche deixa claro sua opinião acerca da ausência de relação entre a vitória nas armas que se teve na guerra franco-prussiana e uma elevação da cultura.
} 
659) construída justamente sobre proposições de nivelamento e de apequenamento do homem como se tem com Dühring (KSA 10, p. 244).

\section{Dühring: o representante da moral do ressentimento}

Do mesmo modo como fez Dühring em relação a Schopenhauer, ao afirmar que "o juízo sobre o valor da vida é (...) um afeto - ou uma necessidade da vida ou um aborrecimento da vida" e que o ódio à vida é um "movimento da vida que se move contra a própria vida" (KSA 8, p. 133 134; cf.: WL, p. 8), isto é, tomando-o não pela validade ou não de seus juízos, mas pelo que eles revelam, por seu caráter prático, também Nietzsche toma as proposições de Dühring não somente pela verdade que elas revelariam sobre o objeto avaliado, mas pelo que elas revelam sobre quem as enuncia.

Considerado em termos práticos, o pensamento de Dühring seria, segundo Nietzsche, um produto da "moral de animal de rebanho" (ABM, §202) e estaria alinhado a um projeto de autodiminuição do homem (GM, III, §25); e sua tese sobre a origem da justiça, a partir do ressentimento, seria ela mesma um produto do ressentimento, em especial do ressentimento que busca tornar-se dominante por meio da afirmação de determinada concepção de moral e de justiça. A tese de Dühring sobre a justiça seria, portanto, uma proposição moral, a qual revela, por princípio, uma inimizade para com a vida, uma forma de aborrecimento para com a vida que busca, contudo, tornar-se universalmente aceita por meio de arautos como Dühring.

De um modo preciso, os escritos de Dühring tomariam parte em uma disputa que tem, por um lado, um tipo superior de homem e o estabelecimento das condições para a sua produção e, por outro, o produto da autodiminuição do homem e as estratégias para a sua proliferação. Uma contraposição que é anunciada no Zaratustra, em seu prólogo, com as denominações "além do homem" e "último homem" (ZA, Prólogo do Zaratustra, §5) e retomada, por exemplo, na seção intitulada "Sobre as tarântulas"38. Entendida no âmbito dessa disputa, a vingança não é um

\footnotetext{
38 Apoiamo-nos na correlação feita por Aldo Venturelli entre o texto do Zaratustra "As tarântulas" e 0 fragmento 12[43] do verão de 1883 (KSA 10, 410-412), no qual Nietzsche refere-se igualmente a uma "vontade de igualdade", porém, substituindo a proposição genérica de "pregadores da igualdade" pelo
} 
direito do indivíduo que sofrera um dano, mas uma acepção geral, associada ao propósito de um nivelamento do homem, propalado pelos "pregadores da igualdade", que "lançam suas injúrias contra todos os que não são [seus iguais]" (ZA, Das tarântulas), com a meta fechar as portas para qualquer tipo superior de homem.

O mesmo tipo investigação que aponta um caráter prático nas proposições de Dühring com o seu subsequente engajamento por um ideal de homem, ganha destaque especialmente em algumas passagens de Para a genealogia da moral. Um primeiro exemplo encontra-se na seção 11 da segunda dissertação, quando Dühring aparece no texto associado ao propósito de "santificar a vingança em nome da justiça" (GM, II, §11), e um segundo na seção 14 da terceira dissertação, quando, Nietzsche refere-se ao professor de Berlim como um antisemita, fanfarrão da moral e apóstolo da vingança.

$\mathrm{Na}$ seção 11 da segunda dissertação da Genealogia da moral, Nietzsche remete aos "anarquistas e antisemitas", dentre os quais se destaca Eugen Dühring, a reedição da tentativa de santificar a vingança utilizando para isto a estratégia de conferir a ela o nome de "justiça", como tinham feito anteriormente os cristãos, conforme é relatado na seção 14 da primeira dissertação. Segue-se, portanto que, para Nietzsche, o procedimento de Dühring sequer constitui uma novidade, correspondendo, antes, à retomada daquilo que estaria em ruínas, em função do desgaste sofrido pelo cristianismo, agora, porém, com uma roupagem de cientificidade. Assim, mesmo com a "nova nuance de equidade científica", o que Dühring e seus pares fazem não atende aos princípios de imparcialidade exigidos pelas ciências, mas é marcado pela "parcialidade", podendo ser caracterizado, enfim, como uma nova tentativa "em favor do ódio, da inveja (...), do rancor [e] da vingança", a qual, como as anteriores, também nasce "do próprio espírito do ressentimento" (GM, II, §11).

O que faz Dühring, portanto, é a renovação de um empreendimento que parecia estar em ruínas. Um empreendimento no qual o ressentimento deixa de se apresentar como um mero afeto reativo, como negação da ação, para mostrar toda a potencialidade de um fenômeno ativo, capaz de impor

artigo nominativo "ele", numa clara remissão a Dühring, segundo Venturelli (VENTURELLI, 2003, P. 222). 
significados a partir de sentimentos como "ânsia de domínio, cobiça e outros semelhantes" (GM, II, §11) e de fazê-lo, agora, com uma eficiência maior do obteria na roupagem ultrapassada do cristianismo.

Na mesma seção 11 da segunda dissertação ${ }^{39}$, é possível observar sinais da separação entre a crítica voltada diretamente aos efeitos práticos das proposições dos membros daquele partido que Nietzsche combate e a argumentação teórica desenvolvida contra a tese de Dühring acerca da origem da justiça. De fato, após afirmar que aquela "nuance de equidade científica (...) provém do próprio espírito do ressentimento" e também que suas considerações desenvolvidas ali seriam "contra essa tendência em geral", ou seja, após considerar o caráter puramente prático de Dühring e seus partidários, Nietzsche retoma sua argumentação contra as teses de Dühring, voltando, somente então, a argumentar "por amor à verdade" (GM, II, §11). ${ }^{40}$

\footnotetext{
${ }^{39} \mathrm{Ao}$ elencarmos alguns pontos específicos nos quais se revela o interesse prático de Nietzsche por seu adversário, não estamos perdendo de vista que toda a Genealogia é um escrito que busca efeitos práticos, um "escrito polêmico" que toma seus adversários por tais efeitos e não para fazer alguma análise de suas teses e se posicionar teoricamente sobre elas.

${ }^{40}$ A expressão "clichê comunista de Dühring", na seção 11 da segunda dissertação da Genealogia, remete precisamente à ideia de igualdade propalada por Dühring e não ao que hoje é entendido como um socialismo científico e associado a Marx e Engels. O mesmo que se tem com o termo "comunismo" que deve ser lido tendo em vista o seu significado no pensamento de Dühring e também de Lassale (Cf.: OTTMANN, 2000, p. 262). A questão sobre o quanto Nietzsche conhece dos socialistas alemães é proposta, em primeira mão, por Heinrich Hengster a Franz Overbeck em carta de 24 de junho de 1889. $\mathrm{Na}$ ocasião, Heinrich Hengster pergunta se Nietzsche teria tido um contato pessoal com Eugen Dühring e também se Nietzsche teria feito algum estudo aprofundado da obra dos socialistas alemães, citando entre eles: Ferdinand Lassalle, Carl Rodbertus, Karl Marx e Friedrich Engels (Appud Curt Paul Janz, Friedrich Nietzsche Biographie, III, p. 336-337). Deve-se acrescentar ainda que no contexto analisado, 0 termo socialismo é tomado do ponto de vista ético e como uma reedição do ideal cristão, conforme é possivel de se verificar em um fragmento do período: "o ideal socialista não é mais do que um grosseiro mal-entendido do ideal moral cristão" (KSA 12, p. 148). Assim, não seria correto imaginar que da crítica de Nietzsche ao socialismo pudesse desprender-se alguma forma de afirmação do capitalismo, especialmente porque o capitalismo, tomado a partir da interpretação de Nietzsche, teria como meta a produção do "último homem" (ZA, Prólogo do Zaratustra, §5). Do ponto de vista da moral e da cultura, o que se observa nas afirmações é que o socialismo seria uma contraposição ao egoísmo e que visaria o "aniquilamento formal do indivíduo" (HH, I, §473). Neste sentido, é de se notar que em várias passagens o socialismo é associado ao despotismo, desde Platão, ou ao "terrorismo extremo" (HH, I, §473), a formas de governo que se servem da precariedade da educação do povo para atingirem seus objetivos, segundo Nietzsche, "para o jogo perverso que deverão jogar" ( $\mathrm{HH}, \mathrm{I}, \S 473)$. Assim, a crítica do filósofo ao socialismo, precisaria ser lida preferencialmente no campo da moral, como uma defesa do indivíduo (KSA 13, 233) e dos impulsos individuais, e também como a afirmação da cultura entendida como cultivo de um tipo destacado de homem.
} 
A segunda passagem na qual se acentua o caráter de uma contraposição prática a Dühring é a seção 14 da terceira dissertação da Genealogia da moral, quando Nietzsche retoma a questão da "mais malévola conspiração" que ocorre justamente onde "pululam os vermes da vingança e do rancor" e que é a "dos sofredores contra os bem constituídos e vitoriosos" (GM, III, §14). Nessa seção, o filósofo volta a utilizar a metáfora da falsificação afirmando que a estratégia, naquela conspiração, consistiria em tomar os sentimentos de rancor e desejo de vingança e em apresentá-los como se fossem "amor, justiça, sabedoria, superioridade", em resumo, como uma moeda falsa que imitaria o "ouro da virtude", mas que, de fato, não teria valor algum. Também nesse caso, Dühring, é o nome utilizado por Nietzsche para caracterizar o tipo de homem próprio ao "espaço consagrado às ciências", que "fala muito de justiça" e que é, contudo, um falsificador e, de fato, um "apóstolo da vingança" (GM, III, $\S 14)$.

Como nas outras passagens mencionadas anteriormente (ZA, Das Tarântulas; GM, I, §14 e GM, II, §11), também nessa seção Nietzsche ressalta que tais homens, "são homens do ressentimento", "sedentos de vingança", que se apresentam "disfarçados de juízes", trazendo na boca, segundo ele, "como baba venenosa, a palavra "justiça". Homens nos quais vibra um mundo de "subterrânea vingança" (GM, III, §14), que não tem por meta o mero revide de uma ofensa e que não pretende se apropriar de um aspecto da vida, mas "da vida mesma" (GM, III, §11). Entre tais homens, Dühring ganha novamente destaque como "o primeiro dos fanfarrões da moral que hoje existe, inclusive entre seus iguais, os antisemitas" e também como aquele que "que na Alemanha atual faz o uso mais indecoroso e repugnante do bumbum moral" (GM, III, §14).

\section{Considerações finais: breve retorno à questão das fontes}

Não há dúvidas de que Dühring foi uma importante fonte para Nietzsche, como se verifica nos textos do período de Humano, demasiado humano, conforme mostra Volker Gerhardt (1983) e Aldo Venturelli (2003) e também nas ideias de comunismo e de anarquismo que se encontram nos escritos de Nietzsche (OTTMANN, 2000). Para além dessa influência direta, contudo, buscou-se nesta investigação apontar o papel de Dühring na filosofia de Nietzsche num momento em que ele é alvo de uma crítica dura 
e contundente, que atinge suas teses e o próprio pensador, tanto por sua atuação como intelectual quanto porque Nietzsche o considere um representante da moral de rebanho. Um papel, que pretendemos sintetizar em três pontos, apresentados aqui à guisa de considerações finais deste estudo.

Primeiro: independentemente até mesmo do fato de Nietzsche reconhecer alguma influência de Dühring sobre seu pensamento em 1887, o fato é que ele confere ao professor de Berlim uma distinção especial ao elencá-lo como adversário, do mesmo modo como o faz com outros adversários, como é o caso, por exemplo, de David Strauss na primeira de suas Considerações Extemporâneas. No caso de Dühring, esse reconhecimento se dá pela leitura cuidadosa de sua obra, pressuposto da crítica às suas teses, profundamente conhecidas por Nietzsche, e pelo olhar atento ao próprio Dühring, um pressuposto indispensável para a caracterização do personagem que ganhará corpo no contexto da crítica de Nietzsche à moral.

Segundo: Nietzsche utiliza contra Dühring o mesmo tipo de análise que o próprio Dühring havia utilizado contra Schopenhauer em 1865. Da mesma forma, como vimos em nossa exposição, também Dühring é tomado por Nietzsche não somente por suas teses, mas pelo que elas revelam do seu autor, como proposições oriundas do ressentimento e da sede de vingança.

Terceiro, e talvez o mais importante, Dühring direciona Nietzsche para uma discussão sobre o ressentimento que dificilmente se desdobraria a partir apenas da leitura de outras fontes como Dostoiévski ${ }^{41}$, por exemplo. Isto porque o professor de Berlim considera o ressentimento, de princípio, não tanto por seu aspecto psicológico, mas em função de sua ligação com a origem da justiça. Dessa forma, sem desconsiderar o aspecto da inibição da ação, mas partindo dele, Dühring inaugura uma análise do ressentimento tendo em vista os efeitos sociais produzidos por ele ${ }^{42}$, algo extremamente importante para as análises de Nietzsche de 1887.

Ou seja, mesmo numa época em que não é recebido com entusiasmo por Nietzsche, nem fornece a ele qualquer "modelo" teórico, Dühring - e

\footnotetext{
${ }^{41}$ Cf.: PASCHOAL, 2010.

42 Desenvolvemos o tema do ressentimento como um fenômeno social no texto apresentado no evento "Assim falou Nietzsche VI", ocorrido entre 16 e 18 de novembro de 2009 na UNIRIO e no ensaio a ser publicado no livro derivado do evento, que está no prelo.
} 
suas teses - continua tendo sua importância reconhecida pelo filósofo. $\mathrm{O}$ professor de Berlim continua oferecendo instrumentos para o trabalho de Nietzsche e ocupando um lugar privilegiado em sua argumentação, tanto como tese a ser refutada, quanto como sintoma a ser combatido. 


\section{Referências:}

BRUSOTTI, M. Die Leidenschaft der Erkenntnis. Berlin / New York: Walter de Gruyter, 1997.

. "Ressentimento e vontade de nada", in: Cadernos Nietzsche, São Paulo, 8: 3-34, 2000.

DÜHRING, E. Der Werth des Lebens. Breslau: E. Trewendt, 1865.

. Cursus der Philosophie als streng wissenschaftlicher Weltanschauung und Lebensgestaltung. Leipzig: Erich Koschny, 1875.

. Der Werth des Lebens. 4. Aufl. Leipzig: O. R. Reisland, 1891.

ENGELS, F. Herrn Eugen Dührings Umwälzung der Wissenschaft (Anti-Dühring), in: Karl Marx; Friedrich Engels Gesamtausgabe (MEGA). Band 27. Berlin: Dietz Verlag, 1988.

GERHARDT, V. Das "Princip des Gleichgewichts". Zum Verhältnis von Recht und Macht bei Nietzsche, in: Nietzsche-Studien, Berlin, 12: 111-133, 1983.

GIACOIA JUNIOR, O. "A Auto supressão como catástrofe da consciência moral”, in: Estudos Nietzsche, vol. 01, n. 01, p. 73-128, 2010.

HANSHE, Rainer J. (Compilador). Nietzsche's Library. 2007. Disponível em: http://www.nietzschecircle.com/Pdf/NIETZSCHE_S_LIBRARY.pdf. Acessado em setembro de 2010.

JANZ, C. P. Friedrich Nietzsche Biographie. III Band. 2. Auflage. München/Wien: Carl Hanser Verlag, 1993.

KOECHE, C. Zeit des Ressentiments, Zeit der Erlösung. Berlin/New York: Walter de Gruyter, 1994.

NIETZSCHE, F. Sämtliche Werke. Kritische Studienausgabe (KSA) Herausgegeben von Giorgio Colli und Mazzino Montinari. Berlin: Walter de Gruyter, 1999. 15 Bände.

. Sämtliche Briefe. Kritische Studienausgabe (KSB) Herausgegeben von Giorgio Colli und Mazzino Montinari. Berlin: Walter de Gruyter, 1986. 8 Bände. OTTMANN H. (Org.) Philosophie und Politik bei Nietzsche. 2. Aufl. Berlin / New York: Walter de Gruyter, 1999.

. Nietzsche Handbuch. Sttutgart/Weimar: Verlag J. B. Metzler, 2000.

PASCHOAL, A. E. Transformação conceitual, in: Revista Trágica: Estudos sobre Nietzsche, Rio de Janeiro, Vol. 2, $\mathrm{n}^{\mathrm{o}}$ 2, p. 17-30, 2009. Disponível em: http://tragica.org/artigos/04/02-antonio-paschoal.pdf. Acessado em Novembro de 2010. 
. "Dostoiévski e Nietzsche: anotações em torno do "homem do ressentimento"”, in: Estudos Nietzsche, Curitiba, vol. 01, n. 01, p. 199-223, 2010.

VENTURELLI, A. Asketismus und Wille zur Macht. Nietzsches Auseinandersetzung mir Eugen Dühring, in: VENTURELLI, A. Kunst Wissenschaft und Geschichte bei Nietzsche. Berlin: Walter de Gruyter, 2003, p. 203-237.

Email: antonio.paschoal@pucpr.br

Recebido: Abril/2011

Aprovado: Maio/2011 